\title{
ACQUISITION OF WH-QUESTIONS BY SECOND LANGUAGE SPEAKERS OF ENGLISH IN PAKISTAN
}

\author{
Azhar Pervaiz $^{1^{*}}$, Abdul Ghaffar Ikram ${ }^{2}$, Naima Batool ${ }^{3}$, Sadia Saeed ${ }^{4}$ \\ ${ }^{1 *}$ Assistant Professor, Department of English, University of Sargodha, Pakistan; ${ }^{2}$ MPhil Scholar, International Islamic \\ University Islamabad, Pakistan; ${ }^{3}$ Lecturer, Department of English, University of Mianwali, Pakistan; ${ }^{4}$ Lecturer in \\ English, Govt. Associate College for Women, Farooka, Sargodha, Pakistan. \\ Email: "azhar.pervaiz@uos.edu.pk
}

Article History: Received on $26^{\text {th }}$ May 2021, Revised on $11^{\text {th }}$ June 2021, Published on $21^{\text {st }}$ June 2021

\begin{abstract}
Purpose of the study: The purpose of the current study is to investigate the acquisition of Wh-questions of English by Urdu L1 speakers in Pakistan. Acquisition of different syntactic structures has been an attractive area of interest for the scholars working in the area of second language acquisition. The study draws on approaches of Universal Grammar (UG) and Second Language Acquisition (SLA). The researchers aim at finding out whether the second language is acquired in the same way as the first language or not. Both Urdu and English allow Wh-questions formation but the placement of the Wh-word is completely at a different position. Urdu is an in-situ language that does not allow Movement of the Wh-word, and English allows the Movement of the Wh-word. So, this study highlights whether speakers of Urdu can acquire the structures of Wh-questions or not.
\end{abstract}

Methodology: The study uses a mixed-method research design, and the data was collected from the speakers of Urdu who speak it as their native language in order to draw the findings. The current research employs a questionnaire that is divided into two parts: elicitation task and grammatical judgement task. For the elicitation task, the students were provided with the statements with the underlined words of which they had to form Wh-questions and for the second, a task was designed on the basis of the lickert scale and it was designed to judge the grammar of the students. The population of this study is limited to speakers of Urdu who speak English as their second language and the sample was selected from the vicinity of Sargodha city of Pakistan.

Main Findings: The results of this mixed-method study reveal that students face problems while forming and identifying Wh-questions, despite compulsory education in English. The findings of the current study supported the partial access hypothesis.

Applications of this study: The study is very important in the area of second language acquisition and informs how the speakers of the English language as a second language acquire the Wh-question structure. The study can be applied in designing teaching materials for the learners of English as a second language besides informing the language software modulation in order to ease the language learning process.

Keywords: Acquisition, Wh-questions, English as Second Language, Movement Principle, Extraction Principle, Wh insitu Language.

\section{INTRODUCTION}

Language acquisition has been a curious, an interesting, and provocative issue for many researchers, especially for linguists and applied linguists. This study is designed to find out the acquisition of Wh-questions by the second language learners, i.e. the Urdu L1 speakers. It also focuses on the operations performed by the Universal Grammar in the acquisition of a second language. The world is becoming multilingual in which a multilingual can perform well (Abbas et al., 2020). Likewise, Pakistan is a multilingual country in which, worldly spoken language, English has occupied a nabob-like place. It is taught in every school, college, and university as a compulsory subject. Official dealings in the offices are also done in the English language (Abbas \& Iqbal, 2018).

Second language acquisition (henceforth SLA) has emerged as an essential area of research in applied linguistics, but unfortunately, there is a dearth of research in this area in Pakistan. The general aim of SLA is that how we acquire the second language and whether it is easy for the second language learners to learn the second language or not. Mitchell and Miles (1998) propounded that not only mind is involved in learning the second language but also other variables play their role in learning the second language, which involves age, motivation, method of teaching, and many others. Theories and modules of Universal grammar (UG henceforth) within the research area of SLA are derived from linguistics; explain that UG holds a separate place in the brain and no other variables are involved in learning a language (Abbas et al., 2011).

There are even different hypotheses of Universal Grammar regarding the acquisition of the second language, and none of them is higher to its sister hypothesis in strengths or weaknesses: full access hypothesis (Schwartz \& Sprouse, 1996), no access hypothesis (Bleyvroman, 2000) and partial access hypothesis (Eubark, 1996). The current study aims at investigating the acquisition of Wh-questions by L2 learners (Urdu speakers) who are living in Sargodha (a city of Pakistan). Urdu is the national language of Pakistan and is used in every region of Pakistan (Abbas et al., 2018), even after having different regional languages. This is an Indo-Aryan language, and it shares much of its structure with other 
Indo-Aryan languages like Persian and Hindi. The word-formation, its order, arrangement of sentence structure, and the most essential thing which is the subject of discussion in this research is question formation is the same in almost all the Indo-Aryan languages. We can find many similarities in Turkish and Urdu languages in the formation of Wh-questions. Gedik says, "The Turkish language is Wh in-situ language because it does not allow the movement of wh-words at the start of the question" (Gedik, 2018, p. 2).

Urdu is an "in-Situ" (does not allow movement of Wh-particles from the canonical position to the specifier's position and maintains its base position) language, but English is not. Urdu does not observe the extended projection principle, empty category principle, and subjacency principle. Further, it does not allow the Movement in Wh-interrogatives. Cook and Newson (2007) explain that the English language follows extended projection, empty category, and subjacency principles, which help the Wh-particle to move from its canonical position to the specifier position of complement phrase (CP). Urdu observes SOV (subject+object+verb) word order, but English follows SVO word order in a sentence which can become a problem in acquisition. This study will investigate whether Urdu speakers observe subject auxiliary inversion (SAI) in the formation of English Wh-interrogatives or not. Lastly, the research will also highlight the importance of UG in the acquisition of a second language and the role of language-specific rules of the first language in the acquisition of the second language.

\section{LITERATURE REVIEW}

The acquisition is defined as the operation of mental activity (also known as the cognitive operation) through which we acquire knowledge and skills (Hornby, 2010), while language acquisition is the mental process that gives humans the ability to apprehend and dig out the structures of language (Chomsky, 1957). Chomsky said, "language acquisition is a matter of growth and maturation of relatively fixed principles and capacities, under appropriate external conditions" (Chomsky, 2009, pp. 101-102). So far as the Second Language Acquisition (SLA) is concerned, it is the process by which non-native speakers acquire a second language. We can say that the second language is the target for the native speakers of other languages to learn it. Jalal (2012) asserts that the vital mystery for todays' linguists is the acquisition of a second language, and this is the issue on which there is no consensus about its acquisition because different hypotheses of UG and cognitive theory are available but not fully proved.

According to Chomsky (1981), the question of first language acquisition is discussed under the Universal Grammar in the theory of Principles and Parameters (P\&P). Chomsky explained (as cited in Cook \& Newson, 2007), "Universal grammar is made up of $\mathrm{P} \& \mathrm{P}$ model: Principles are the universal rules that are common to every language, and we have no need to learn them, and parameters are different aspects of language which differ from one language to another" (p. 9). But researchers raised the question of whether a second language is also acquired in the same way or there is some other way of acquiring a second language. The researchers will also address when anyone acquires a second language, then the parameters of the first language interfere in the acquisition of the second language or not. So, the followers of Chomsky came up with different hypotheses regarding this complex proposition.

Full Access Hypothesis states that if the second language learners get the second language precisely as the first language, then UG is involved because it is learned unconsciously. A child learns the first language from the first day of his or her birth, so if we acquire a non-native language as it is, then UG is involved (Schwartz \& Sprouse, 1996). Secondly, some researchers are of the view that second language learners face a lot of problems in attaining a complete command of the second language. So, Universal Grammar does not play any role in language acquisition, and this is called the nonaccess hypothesis (Bley-vroman, 2000). This view is also supported by the research of Schachter (1989, 1990) that he conducted about Wh-acquisition in English on second language learners of many different first languages. The no access hypothesis is also supported by the variable of growing age (Newport, 1990).

Between the two opposite poles, some others believe in the presence of the Partial Access Hypothesis which states that the role of Universal Grammar can never be neglected. Still, they also accept the interferences made by the first language learners in SLA, which leads them to claim that UG is not fully available to second language learners (Eubark, 1996; Johnson and Newport, 1991; Wu, 2008).

A statement that interrogates for information, reply, or response is called an interrogative sentence. There are different rules to form questions. As some questions need the answer in yes/ no, some questions are developed to get detailed information, and there are some questions in which we just need confirmation of already provided information, etc. So, we follow different structures of word order to form different types of questions. But the most important type of question in which the native speakers of English face a lot of problems at their initial stage of language acquisition is Whquestion (Goodluck, 1991). Radford asserts, "children who are the native speakers of English, show lack of competence in yes/ no question and in Wh-questions at their initial stage of language learning" (Radford, 1994, pp. 211-212). Not only the native speakers but the non-native speakers also face a lot of troubles in the formation of these questions. According to Klein, "Mostly non-native speakers make errors while using the second language and indulge in the wild or rogue grammar" (Klein, 1995, pp. 87-117).

Movement is one of the most important characteristics of the Universal Grammar, which says that a category can move to the target position (Chomsky, 1981). Chomsky said, "The relationship between the moving element and the original element is called the Movement, i.e., a phrase can move from one position to another (Chomsky, 2000, p. 12). We can 
form Wh-questions according to the Extended Projection Principle (EPP). This principle explains that a clause always carries a noun phrase or determiner phrase at the subject's position after which comes the verb. This allows movement from the base position to the specifier position of CP (Chomsky, 1987).

Chomsky (1957) gave the concept of Transformative Generative Grammar (TGG) in which he combined both phrase structure and T-rules. The theory highlights the formation of all possible correct structures. Yule (2006) presented, "the tree diagram of phrase structure rules and movement of elements" (pp.102-103).

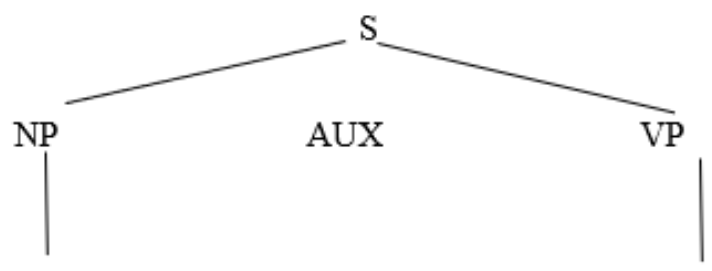

$\{$ Art (Adj) N, Pro, PN\}

$\{\mathrm{V} \mathrm{NP}(\mathrm{PP})(\mathrm{Adv})\}$
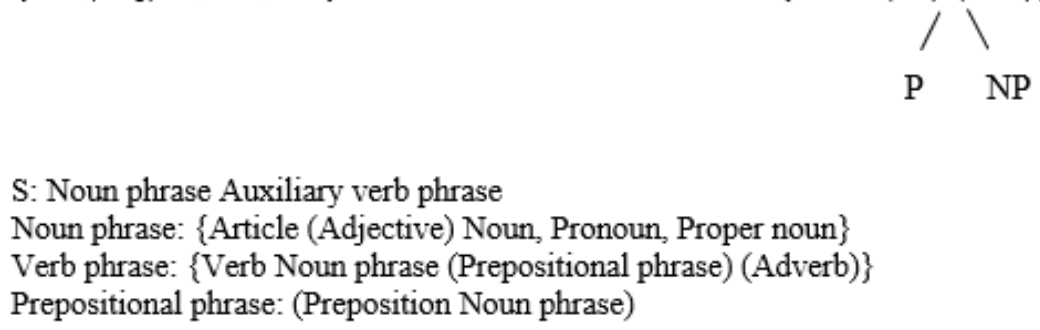

$\mathrm{S}$ : Noun phrase Auxiliary verb phrase Noun phrase: $\{$ Article (Adjective) Noun, Pronoun, Proper noun\} Verb phrase: \{Verb Noun phrase (Prepositional phrase) (Adverb)\} Prepositional phrase: (Preposition Noun phrase)

Figure 1: Representation of Syntax by Yule (2006)

This is a tree diagram or the static representation of the sentence, and if we want to show the Movement, we can take the auxiliary at the start or the Wh- word/ phrase at the start. This Wh-movement is called transformation (Chomsky, 1957). As Yusa argues, "the main theme of generative grammar is the Wh-movement" (Yusa, 1999, p. 289). This static representation or representation by the tree diagram was much followed in the past. But it could just describe and not explain the reasons for the movement of wh-words or subject auxiliary inversion, so the Minimalist Program was forwarded by Chomsky (1995, 2000).

In the Minimalist Program, this theory of the movement of the Wh-word has occupied an important place. Wh-word or phrase moves to the specifier position and takes the place of C in CP (Radford, 1997). In 1981, Chomsky defined three types of movements in his Government Binding Theory (Chomsky, 1981). Cook and Newson have explained these movements as follows, "A-movement (DP moves to the argument position), A-movement (in this phrase moves to the non-argument position), and Head movement (a head of phrase moves instead of the whole phrase) and these all movements somehow explained the formation of interrogative sentences" (Cook \& Newson, 2007, p. 133).

This theory also overcomes the problems which were in the structures of generative grammar. Chomsky came up with the new model to present structures of sentences (Chomsky, 1981).

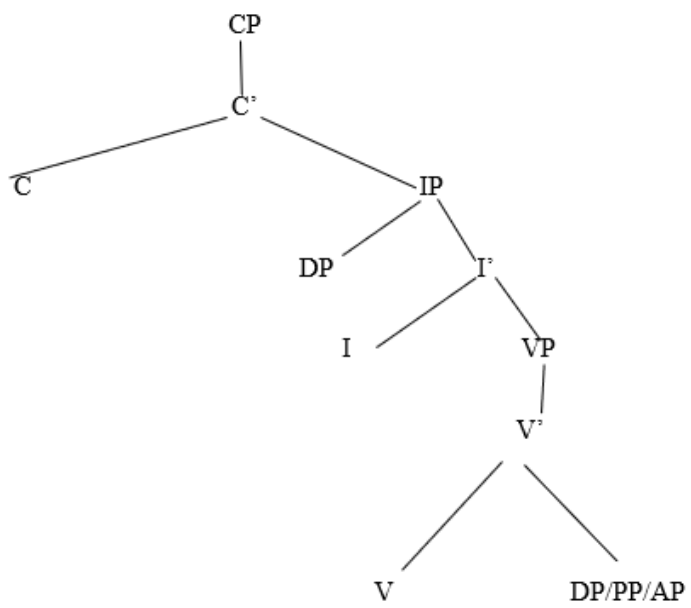

Figure 2: Representation of Syntax by Chomsky (1981) 
As the current research aims at interrogating whether the second-language speakers of the Urdu language in Pakistan can form right or wrong Wh-questions while observing the rules of SAI. There are different ways of forming Wh-questions in English and Urdu because the first one allows movement, and the second allows no movement. After all, it is an insitu language. The question that starts with Wh-word is called Wh-question. These questions are asked to get information or confirmation for already provided information. Its elements are what, who, when, where, why, and how. As in English, the auxiliary or Wh-word comes at the start of a sentence because of ECP (Wh-word occupies empty of specifier of $\mathrm{CP}$ ) and subjacency principle, but the situation is not the same for every language. There are different types of Wh-questions.

1. The Wh-subject question is that in which the Wh-word takes the position of the subject. For example: who is at the door?

2. The Wh-object question is that in which the Wh-word takes the position of an object and moves from that position to the initial position.

\subsection{He is playing what?}

What is he playing (It follows movement and subject auxiliary inversion)?

2.2 He likes swimming.

What does he like?

3. Wh-expression can also take the position of the object of a prepositional phrase and can also occur at the place of adjunct. For example:

He told her plan to Sana (Prepositional phrase).

He told his plan to whom?

To whom did he tell his plan?

He will perform tomorrow (Adjunct position). When will he perform?

But there are some situations in which Wh-movement is not done. First, there is an echo question (you hit whom?); secondly, there is a quiz question (Quaid was born in which city?), and thirdly, there are multiple Wh-expressions (who murdered whom?). Figurative representation of example 2.2 He likes swimming.

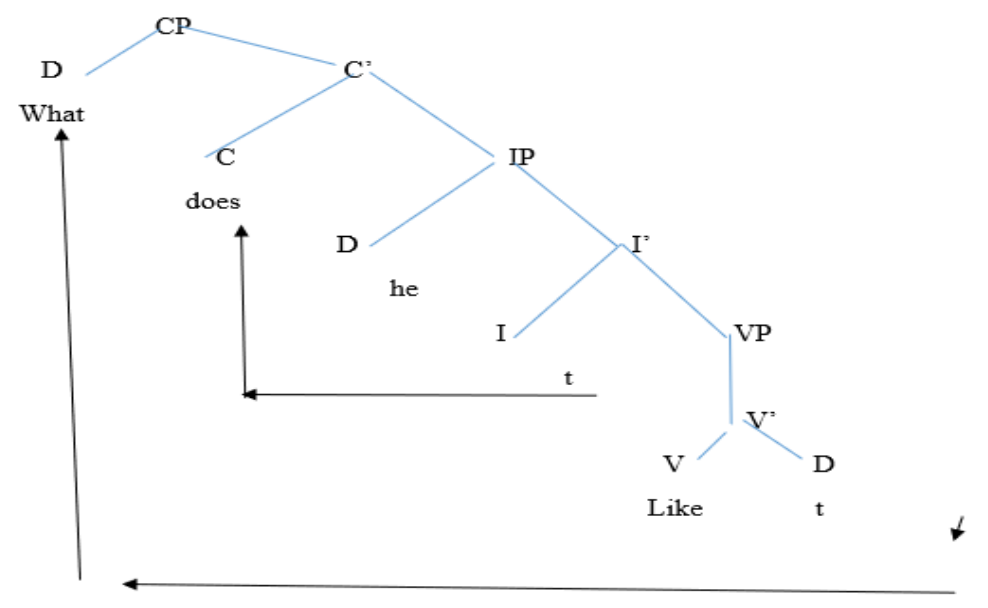

Figure 3: Representation of Movement

Radford (1997) explained the process of movement and subject auxiliary inversion. In the above figurative representation, what as Wh-element has to move from the DP of VP to the specifier of CP and does as dummy auxiliary has to move from the head of the inflection phrase to the head of the complementizer phrase. The reason for this is that due to the strong tense feature of the head of CP and the question particle Q (Chomsky, 1995). Now, if we observe the syntax structure of Urdu, we will find that it shares most of its syntactic features with other Indo-Aryan languages like Hindi and Persian (Bukhari, 2009). In Persian, Wh-word is used before the verb because it follows like Urdu SOV word order. There are also some other Indo Aryan languages in which the same structure is followed. Turkish also follows the same parameter (Gedik, 2018). All these languages obey the principles of the head-final parameter. Language users of these languages use objects or complements before head. They are related to each other in one more parameter, and that is of wh in-situ. They do not allow the movement of wh-words at the subject position. As Gedik tells us about the Turkish language, "it is an in-situ language because it does not allow the movement of wh-words" (Gedik, 2018, p. 2). There are also some other languages in which only adjunct or some grammatical portion is allowed to move as Tatika et al. purport the wh-difference between Chinese and Japanese, "in the Chinese language only wh-adjuncts undergo 
movement and in Japanese whole wh-argument can undergo movement because Japanese observes wh-island effect with wh-arguments" (Tatika et al., 2007, p. 100). So, this research will find out how Urdu speakers whose language structures do not allow wh-movement will form English sentences with wh-movements.

As in English, we form questions to obtain the answer is yes/ no or to get any information; likewise, in Urdu, we have yes/ no questions or Wh-questions, which are translated as K-word questions to get detailed information. The beauty of both these languages, English and Urdu, is that it allows K-word or Wh-word questions, but the first one allows movement; and the second one places it before the verb and does not allow movement. In Urdu, the question indicating $\mathrm{k}$-word comes after pronoun as in this example:

\section{Tum kia kr raha ho?}

You what doing are?

What are you doing?

But when there is an already identified pronoun, then Wh-word comes at the start. It is primarily used in informal conversation.

\section{2. (Tum) kia kr rahe ho? (Identified pronoun)}

*What doing are? (Here You is used as an implied subject because it can be determined from the context) What are you doing? (English)

As we know, a lot of research has been conducted regarding the acquisition of the first language, but there is a dearth of research in the area of second language acquisition. This is important because it will highlight how a second language is acquired; what type of problems non-native speakers face in acquiring a second language; what can be its solution, and do second language speakers acquire language like native speakers? It will also help to prove after long research which hypothesis of Universal Grammar is correct. Taking these considerations into mind, this research work is attempted, so the difference of the speech is identified.

\section{METHODOLOGY}

The research objectives of the current research aim to explore how an Urdu L1 speaker of English language form the Wh-questions; analyze whether an L1 Urdu speaker of English observe Wh-movement and SAI in Wh-interrogatives or not and find out the role of UG and language-specific rules in the acquisition of English as a second language. For this, the current research adopts the mixed research methodology and employs a questionnaire, which is divided into two parts; elicitation task and grammatical judgement task. For the elicitation task, the students were provided with the statements with the underlined words of which they had to form Wh-questions, and for the second, a task was designed on the basis of the Lickert scale, and it was designed to judge the grammar of the students. In the second task, Whquestions were provided with five options: surely grammatical, grammatical, not sure, ungrammatical, and surely ungrammatical, and students had to choose one suitable option. The students were given forty minutes to complete both the tasks, and the data was personally collected by the researchers in two weeks. The questionnaire was validated through the process of pilot testing. The population of this study is limited to speakers of Urdu who speak English as their second language. The institutes selected for this study are located in the vicinity of Sargodha, the city of Pakistan. Due to less time and resources, this research is limited to a sample of 50 students selected conveniently from three colleges. Students were divided into two different groups; twenty-five male and twenty-five female students having ten years of education with English as a compulsory subject. Lastly, they were selected for getting data with the age range of sixteen to eighteen.

\section{FINDINGS AND DISCUSSION}

As mentioned earlier, the data from a sample of fifty college students were collected to explore the acquisition of Wh questions. The questionnaire was divided into two tasks: elicitation task and grammatical judgement task. The details of the findings from both the sections of the questionnaire have been presented and discussed here.

Elicitation task: The first task was designed to check the competence and knowledge of the students in the formation of Wh-questions from a statement. Its primary purpose was to see whether students observe the extended projection principle, Subject auxiliary inversion, and empty category principle or not. The first task was comprised of twenty-five statements with underlined words that were to be turned into Wh-questions. It was further divided according to the two criteria of analysis, on the basis of extraction and complexity, into two types. There were eight subject extraction questions in which the underlined word is the subject, and students were to formulate Wh-question that asked for an answer about the subject. For example:

- Sparrow fell off the wall.

What fell off the wall?

- $\underline{\text { Alia }}$ is coming to see Tina. 
Who is coming to see Tina?

Secondly, there were eight object position questions. Students were asked to extract an object word and formulate a Wh-question that asks for information about the object. For example:

- She looks awesome.

How does she look?

Thirdly, there are six preposition extraction Wh-questions. Prepositional word or phrase was underlined in the statement, and the student would formulate a Wh-question while turning an underlined part into question form. For example:

- I am thinking about my next lecture.

What am I thinking about? / About what am I thinking?

Lastly, there were three adjunct position Wh-questions. An adjunct was underlined in the statement, and the students were to formulate a Wh-interrogative by extracting an adjunct into an appropriate Wh-word. For example:

- He will come tomorrow.

When will he come?

Table 1: Overall success or failure percentage of the participants in the Elicitation task

\begin{tabular}{llll}
\hline No. of informants (50) & & Success & Failure \\
\hline Male (25) & Subject & $70 \%$ & $30 \%$ \\
\hline & Object & $17 \%$ & $83 \%$ \\
\cline { 2 - 4 } & Preposition & $13.33 \%$ & $86.67 \%$ \\
\cline { 2 - 4 } & Adjunct & $31 \%$ & $69 \%$ \\
\hline Average & & $33 \%$ & $67 \%$ \\
\hline Female (25) & Subject & $68.5 \%$ & $31.5 \%$ \\
\hline & Object & $19.5 \%$ & $80.5 \%$ \\
\cline { 2 - 4 } & Preposition & $13.33 \%$ & $86.67 \%$ \\
\cline { 2 - 4 } & Adjunct & $24.67 \%$ & $75.33 \%$ \\
\hline Average & & $32 \%$ & $68 \%$ \\
\hline Overall average of male and female participants & $32.5 \%$ & $67.5 \%$ \\
\hline
\end{tabular}

The above table 1 clearly explains about the competence of students in forming Wh-questions. Overall average, as it is $31.5 \%$, of the student, is comparatively less. Male students are performing better than the female students with a difference of $1 \%$. The greatest successes achieved by the students are in the subject Wh-interrogatives with a percentage of $69.25 \%$. And the lowest percentage is in the preposition extraction questions, and that is $13.33 \%$. If we observe the percentage of students in object questions (18\%) and adjunct questions (28\%), we will find that students have performed comparatively better in adjunct questions than the object and preposition questions. The graphical representation of the table is given in Figure 3.

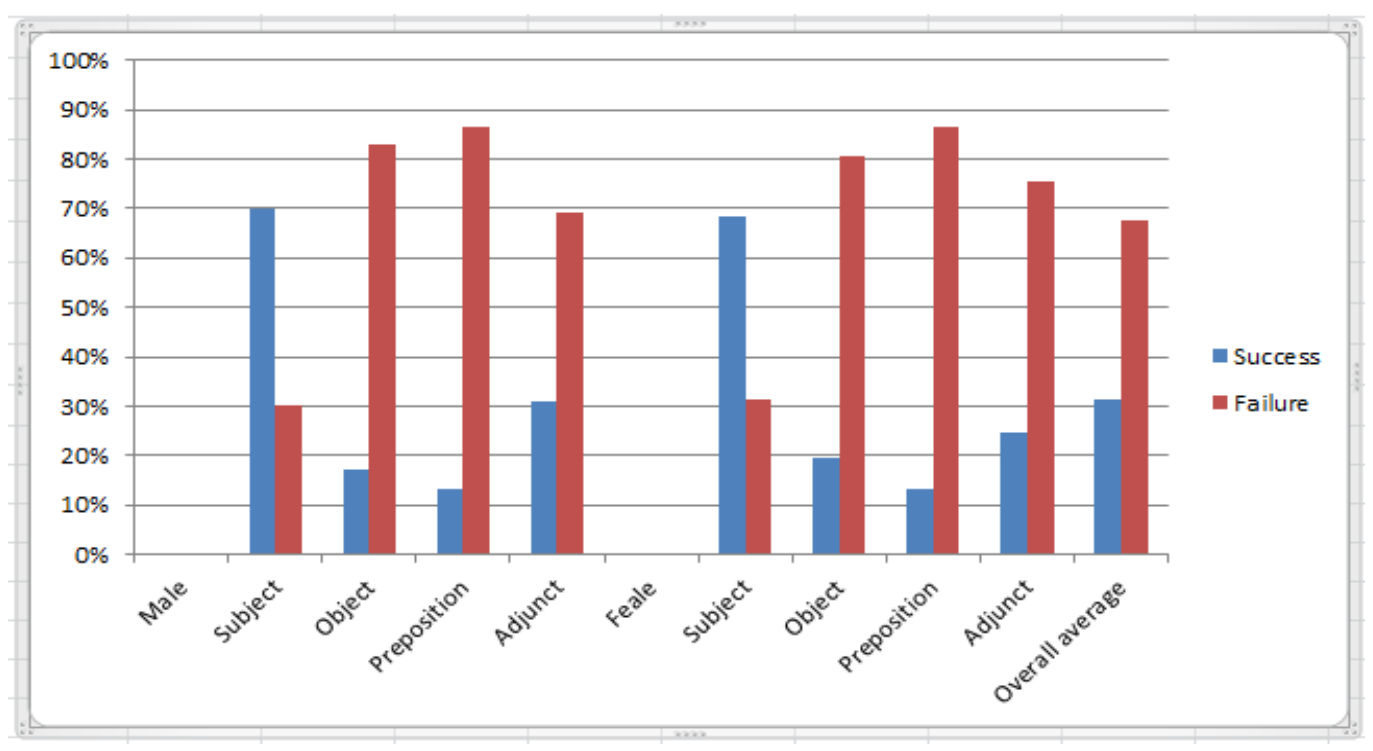

Figure 4: Result of elicitation task according to extraction principle 
The essential and noticeable difference between the subject and object, preposition, and adjunct questions is due to the subject auxiliary inversion. Students are observing the extended projection principle but not SAI, which leads to wrong formations. The percentage of observing SAI is shown in table 2.

Table 2: Overall failure percentage of participants in observing SAI

\begin{tabular}{lll}
\hline No. of informants (50) & & Not successful in observing SAI \\
\hline Male (25) & & \\
\hline & Object & $40 \%$ \\
\cline { 2 - 3 } & Preposition & $25.33 \%$ \\
\cline { 2 - 3 } & Adjunct & $40.67 \%$ \\
\hline Average & & $35.33 \%$ \\
\hline Female (25) & Object & $37.50 \%$ \\
\cline { 2 - 3 } & Preposition & $32.67 \%$ \\
\cline { 2 - 3 } & Adjunct & $54.67 \%$ \\
\hline Average & & $41.61 \%$ \\
\hline Overall average of male and female participants & $38.47 \%$ \\
\hline
\end{tabular}

As we can see, $38.47 \%$ of students used correct auxiliary while converting statement into question but placed it at the wrong position. If we add this percentage to the success rate of students, then we find that it will become $69.97 \%$. The basic question is: why are the students unable to follow SAI even after twelve years of English as compulsory education. The possible reason is that the students are native speakers of Urdu, and their language is in-situ. Urdu does not allow movement of Wh-particles and auxiliary inversion, which leads to non-observance of SAI. Even the researchers have found some students placing the Wh-word at the position of Urdu question during the course of class teaching. This shows that students are less attentive towards UG and more towards their language-specific rules, especially of their L1.

Further, our next aim is to compare the percentage of students in simple and complex questions. These same twenty-five questions were divided into twenty simple and five complex questions. These five questions were designed on the basis of extraction from an argument and adjunct position. Examples related to simple questions are already stated above, but the examples of complex questions are as follows.

- Ali knows that Ayesha believes that Iqra likes English movies.

What does that Ayesha believe that Iqra likes?

Table 3: Overall success and failure $\%$ of students in simple and complex questions

\begin{tabular}{lllll}
\hline \multirow{2}{*}{ No of Informants (50) } & Simple & \multicolumn{3}{c}{ Complex } \\
\cline { 2 - 5 } & Success & Failure & Success & Failure \\
\hline Male (25) & $37 \%$ & $63 \%$ & $28 \%$ & $72 \%$ \\
\hline Female (25) & $38 \%$ & $64 \%$ & $21 \%$ & $79 \%$ \\
\hline Average & $37.5 \%$ & $62.5 \%$ & $24.5 \%$ & $75.5 \%$ \\
\hline
\end{tabular}

The results of table three show that the students are far better in the simple Wh-question formation as compare to complex questions. We have a difference of almost 13\%. Here one thing that is also differentiating is the poor performance of female students in complex questions with the difference of $7 \%$. The result of table 3 is also presented graphically in figure 4.

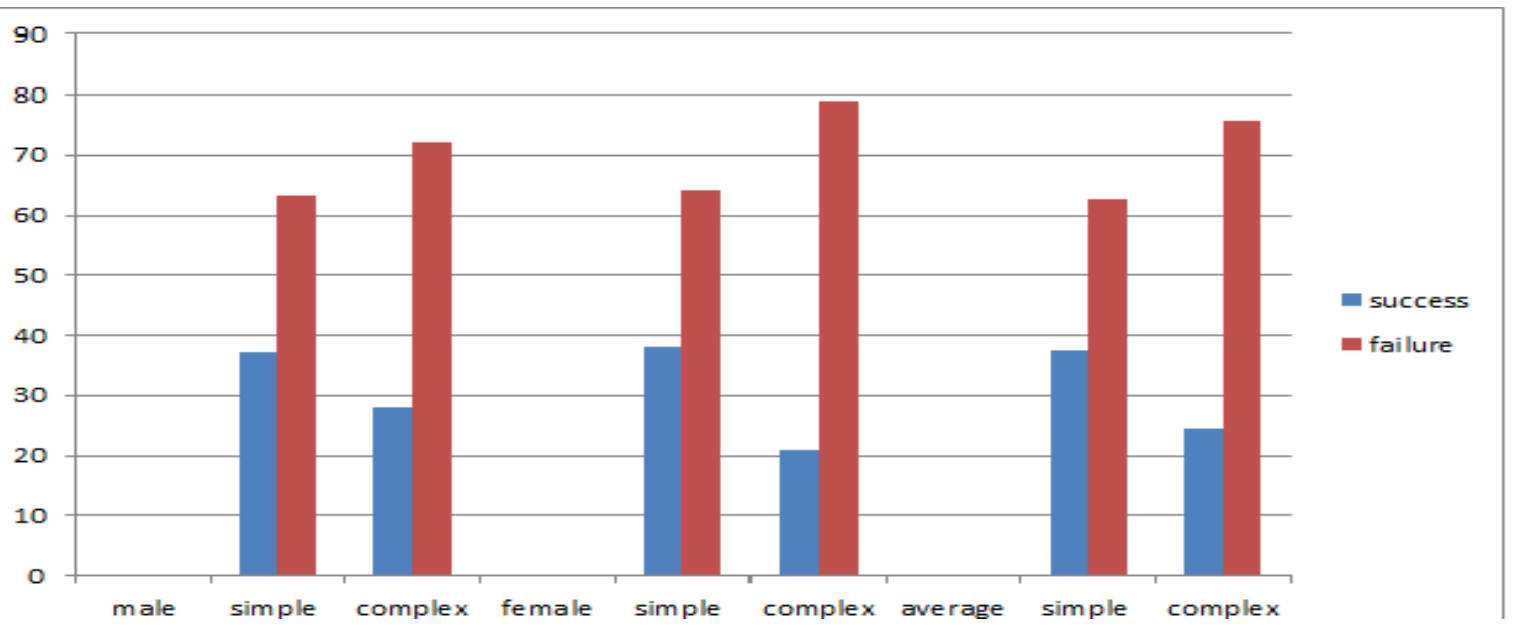

Figure 5: Results of students in simple and complex questions 
So, the overall result of the elicitation task: part one indicates that $31.5 \%$ of students scored correct, and in part two, students scored $37.5 \%$ in simple and $24.5 \%$ in complex questions, shows that there is significantly less role of UG in the acquisition of the second language, but it does have some role. Students are also less aware of SAI and extended projection and subjacency principles. So, the result supports the partial access hypothesis. But there is another task that will clearly make way for the researchers to support one of the hypotheses of UG.

\section{Grammatical judgement task}

The second task designed to see; how much students were able to judge and pick out from the five options: surely grammatical, grammatical, not sure, ungrammatical, and surely ungrammatical; of the given Wh-questions with these numbers assigned 1,2,3,4, and 5 respectively. This was introduced to check the competence level of students in understanding the grammar of Wh-questions. It consisted of thirty-five questions: eleven grammatical and twenty-four ungrammatical questions. Researchers had taken more ungrammatical Wh-interrogatives because it is difficult to judge the wrong part. This task was designed to analyze just Wh-questions based on the extraction principle.

The grammatical judgement task was designed according to the extraction principle: extraction from the argument (subject and object) position, preposition, and adjunct position. There are eight subject Wh-questions taken, fifteen objects, four prepositional, and eight adjunct position Wh-questions which makes thirty-five in total. If the given Whquestion was surely grammatical, the student would tick the first option, and as they feel right, they would tick the other option. This will help us to analyze whether students can judge the ungrammatical and grammatical questions. The grammatical question follows every aspect of grammar in forming Wh-question and ungrammatical questions either follow SAI, ECP, subjacency principle, or all of them. Some of the examples are given in table 4, and these two examples will show how to deal with these questions.

Table 4: Two examples from the designed questionnaire of Grammatical Judgement Task

\begin{tabular}{llllll}
\hline Questions & $\mathbf{1}$ & $\mathbf{2}$ & $\mathbf{3}$ & $\mathbf{4}$ & $\mathbf{5}$ \\
\hline Where did they leave their luggage? & & & & & \\
\hline Whose phone did ring in the class? & & & & & \\
\hline
\end{tabular}

The analysis of the results obtained through excel of this task is presented in table 5. There is the result of fifty students and questions are thirty-five: eight subject questions in which one is surely grammatical and seven are surely ungrammatical, likewise object fifteen in which there is a ratio of five and ten, preposition four into three and one and lastly, there are eight adjuncts which are divided into two surely grammatical and six surely ungrammatical which makes a grand total of eleven surely grammatical and 24 surely ungrammatical.

Table 5: Overall percentages of students in the grammatical judgement task

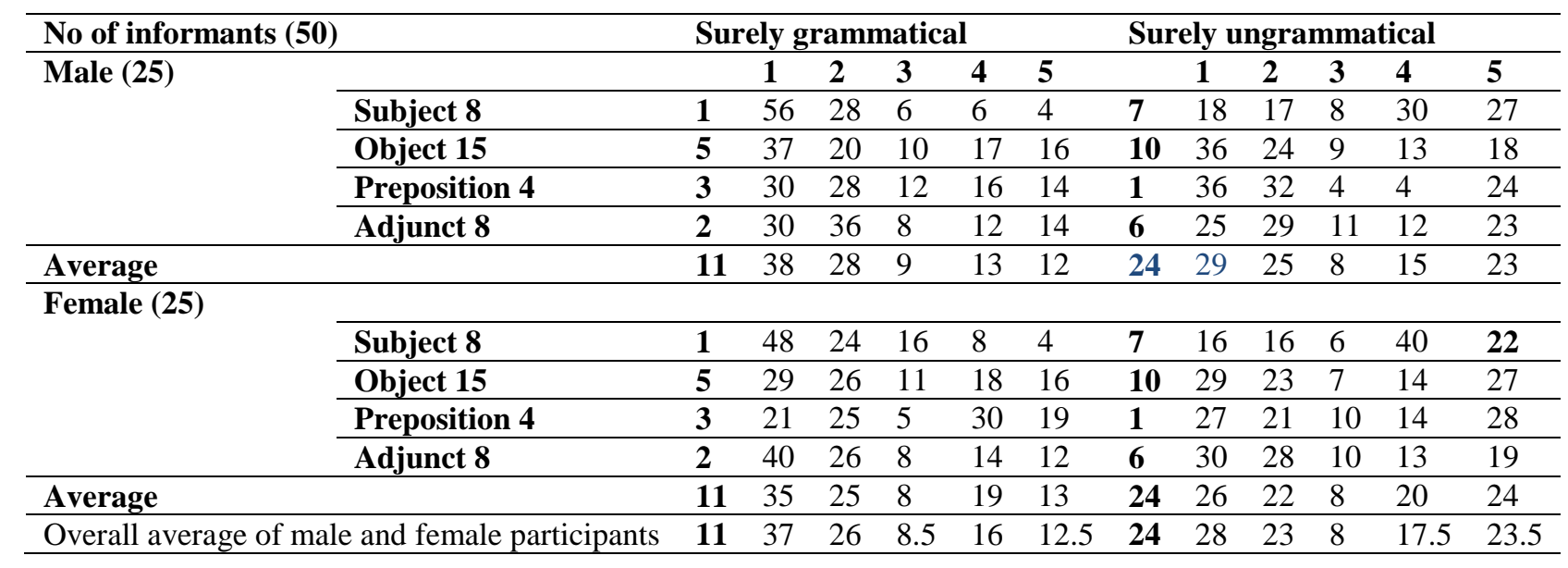

The result of the table five shows the performance of students in both surely grammatical (11) and surely ungrammatical questions (24). If we see the result of surely grammatical questions, we find that male students have performed comparatively better in the subject questions than the female students. $56 \%$ male students and $48 \%$ female have ticked option 1, and if we add option 2 results, it gives us a total of $84 \%$ for male and $72 \%$ for female students. In the object, preposition, and adjunct questions, students have not performed so well. 37\% Males have ticked option 1 of object questions, $30 \%$ of preposition and 30\% of adjunct questions, and $29 \%$ of females have ticked option 1 of an object, $21 \%$ of preposition and $40 \%$ of adjunct questions. This clearly tells us that males have performed better in the subject, object, and preposition questions as compared to adjunct questions. If we add the results of male students of option 2 into 1 , we get $57 \%$ for an object, $58 \%$ for preposition and $66 \%$ for adjunct questions, and of female students $55 \%$ of the object, $46 \%$ of the preposition, and $66 \%$ for adjunct questions, which is far low to subject questions. The result of object and preposition questions tells us, those male students are ahead in the understanding grammar of the Wh-questions. 
Students have again performed well in the subject questions like the elicitation tasks results. Again, the reason is the same as it was in task-1. There is not any involvement of SAI, extraction, and movement principle in subject questions which plays their role in the object, preposition, and adjunct questions. So, students can perform better in subject questions as compared to others. $9 \%$ of Male students have ticked not sure and $8 \%$ of the female which shows their incompetency towards the grammar of Wh-questions. $28.5 \%$ of average students marked options 4 and 5 , which reflects that they don't know about the correct structure. This result also proves the partial access hypothesis of UG, but still, the results of surely ungrammatical questions are left.

The second part of table 5 is about the results of surely ungrammatical questions. 24 surely ungrammatical questions were chosen with the intention that students face more difficulty in recognizing surely ungrammatical questions. Option four and five are acceptable. $27 \%$ of male students marked option 5 of the subject, $18 \%$ of the object, $24 \%$ of the preposition, and $23 \%$ of the adjunct of adjunct questions. $22 \%$ of female students have ticked option 5 of the subject, $27 \%$ of the object, $28 \%$ of the preposition, and $19 \%$ of the adjunct questions. If we add the ticked result of option 4 into 5 , we find that male students have marked $57 \%$ subject, $31 \%$ object, $28 \%$ preposition, and $35 \%$ adjunct and female students give us the total in $62 \%$ subject, $42 \%$ object, $43 \%$ preposition, and $32 \%$ adjunct.

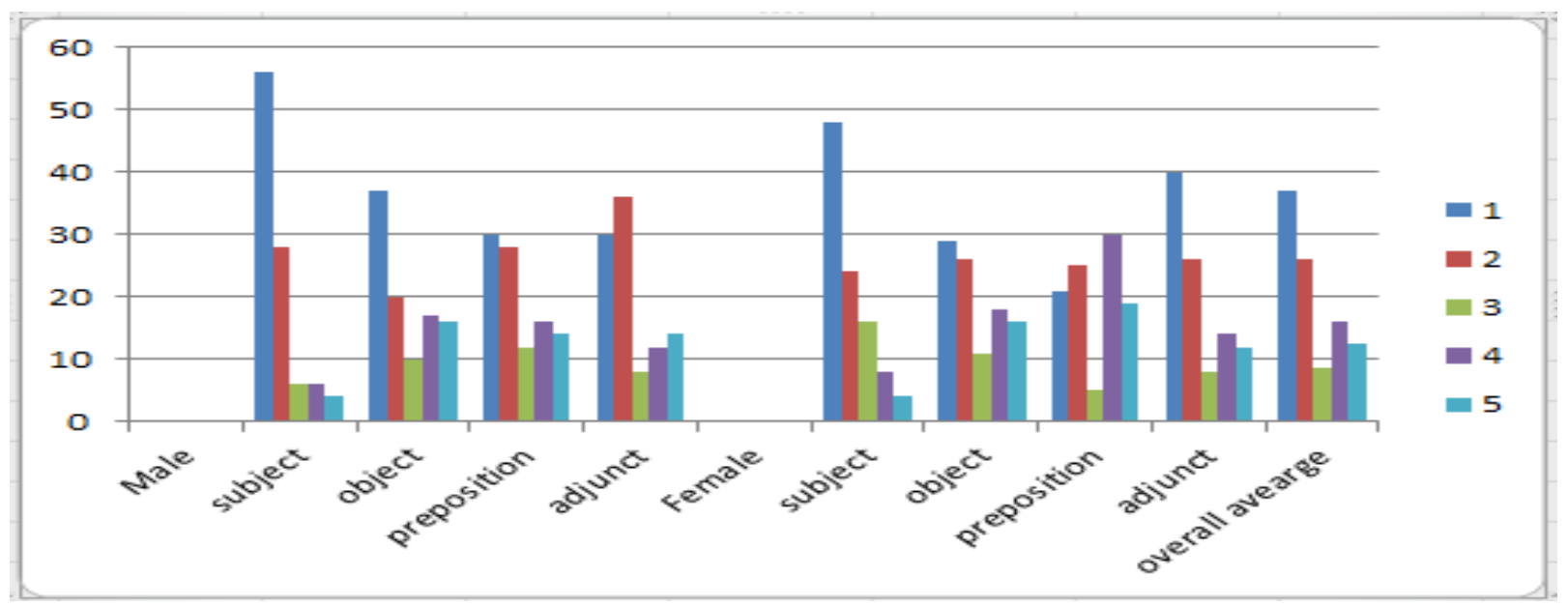

Figure 6: Results of surely grammatical questions

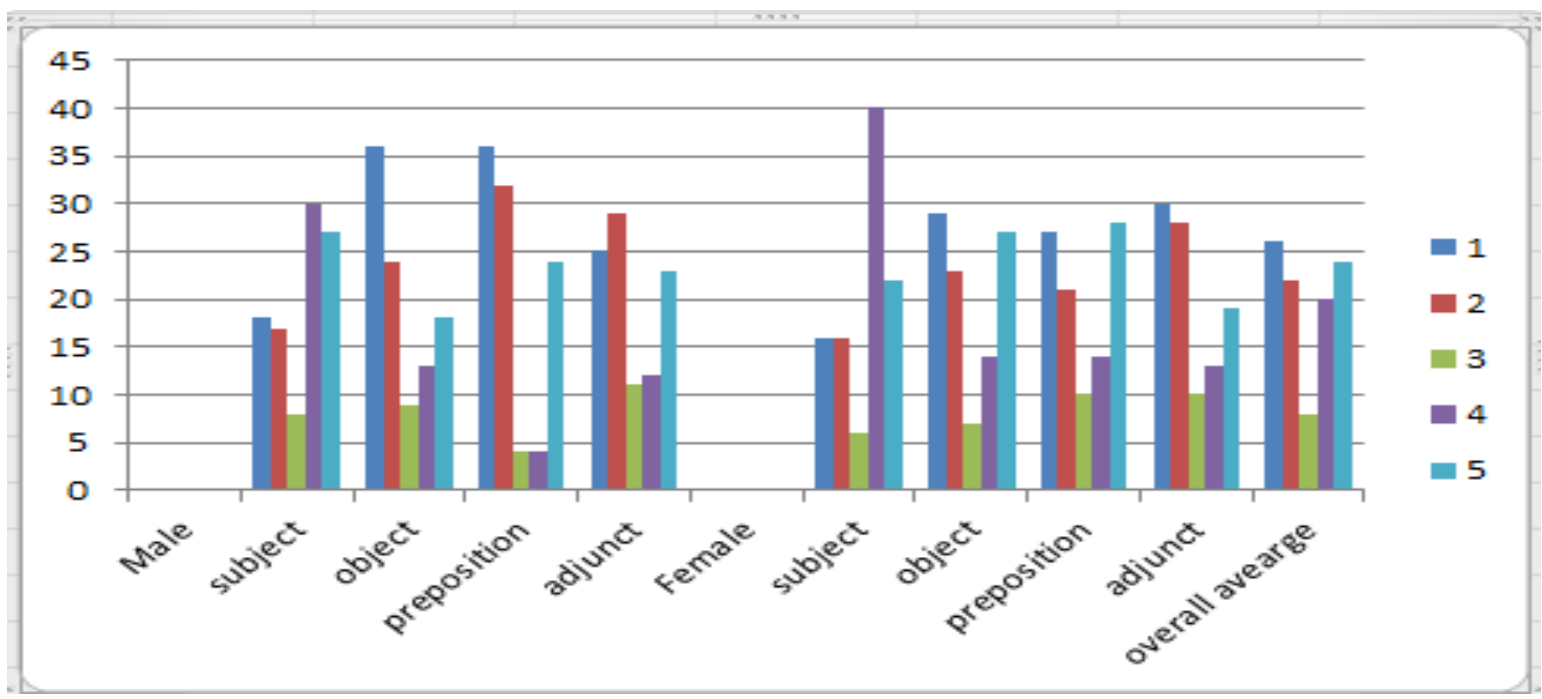

Figure 7: Results of surely ungrammatical questions

The above figures further support the view that students can easily judge grammatical questions but not ungrammatical ones. In some ungrammatical questions, SAI is not followed; in some extraction and empty category principle is also not followed. We find those female students perform better in surely ungrammatical part as compared to the males. This reflects the alertness of females in understanding the tricky questions as compared to the males. Now, if we see the result of the grammatical judgment task, it is again supporting the partial access hypothesis of UG and language specific-rules of their language.

\section{CONCLUSION}

The present study was conducted to explore the acquisition of Wh-questions by the second language speakers (L1 Urdu speakers) and to see whether UG plays any role in the acquisition of Wh-questions. The findings of the current research 
supported the partial access hypothesis and the study of Johnson and Newport (1991), Eubark (1996), and Wu (2008). In the elicitation task, students were provided with 25 statements. They were supposed to turn those statements into Whquestions by replacing the underlined word with a suitable Wh-word. This was designed to check whether students observe the principle of subject auxiliary inversion and extended projection principle. The results show that students face problems while forming Wh-questions. Their success in the extraction task was 32.5\%, and failure 67.5\%. Students performed very well in the formation of subject questions as compared to the other questions because there was no movement of the Wh-word involved. They committed mistakes in placing auxiliary while attempting. They were $38.47 \%$ unsuccessful in using the auxiliary at the right place. The second part of the elicitation task was to check the responses of the students in simple and complex questions. Students performed well with the success of $37.5 \%$ in simple questions and $24.5 \%$ in complex questions. This shows that students cannot follow the empty category principle and extended projection principle in complex questions.

In the grammatical judgment task, 11 ungrammatical statements were taken and 24 ungrammatical, and the results show students performed reasonably well in judging grammatical statements with the success of $63 \%$ of students selecting option one and two and in ungrammatical statements with the success of just $41 \%$ selecting option 4 and 5 . This shows students face problems in the formation of Wh-questions and cannot follow the principles of SAI and ECP. So, our research supports the Partial Access Hypothesis. The possible solution is to provide teaching based on the inductive method if we want to achieve native-like competence. Further research is needed to see the students who performed better: what was their course and how they were taught.

\section{AUTHOR'S CONTRIBUTION}

Azhar Pervaiz developed the concept for the article and helped all other members by assigning and assisting them wherever they required the expertise besides improving the language of the article, running a grammar check and editing for clarity. He developed the introduction section in order to streamline the concept.

Abdul Ghaffar Ikram developed the literature review section of the article.

Naima Batool collected data and analyzed it.

Sadia Saeed wrote the discussion section and developed the reference list.

\section{REFERENCES}

1. Abbas, F. and Iqbal, Z. (2018). Language Attitude of the Pakistani Youth towards English, Urdu and Punjabi: A Comparative Study. Pakistan Journal of Distance and Online Learning, 4(1), 199-214.

2. Abbas, F., Aslam, S. and Yasmeen, R. (2011). Communicative Language Teaching: A Modified Version. Language in India, 11 4), 331 - 341.

3. Abbas, F., Jalil, M. K., Zaki, H. N. \& Irfan, F. (2020). Implicit measure of language attitude: study of Punjabi native speakers by using matched guise technique. International Journal of Innovation, Creativity and Change, 13(1), 194-206.

4. Abbas, F., Pervaiz, A. and Arshad, F. (2018). The competing status of Urdu and English after declaration of Urdu as official language in Pakistan. Journal of Research (Urdu), 34(1), $142-158$.

5. Ahmed, S. N., Abbas, F. \& Naz, F. (2020). Historical development of orthography in English and impact of computer-mediated communication (CMC) on the emerging orthographic patterns in English. PalArch's Journal of Archeology of Egypt 17(11), 162-175.

6. Bhatti, A.M., Abbas, F. \& Rana, A.M.K. (2020). An Empirical study of learning styles used by undergraduate English learners in public sector colleges in Pakistan. Elementary Education Online, 19(3), 1864-1875.

7. Bley-vroman, R., \& Yoshinga, N. (2000). The acquisition of wh-questions by high proficiency non-native speakers of English. Second language research, 16, 3-26. https://doi.org/10.1191/026765800676857467

8. Bukhari, N. H. (2009). The syntax of serial verbs in Gogri. PhD thesis. Newcastle university: UK.

9. Chomsky, N. (1957). Syntactic structures (Janualinguarum 4). Gravenhage: Mouton. https://doi.org/10.15 $15 / 9783112316009$

10. Chomsky, N. (1981). Lectures on Government and Binding. Dordrecht: Foris.

11. Chomsky, N. (1995). The minimalist program. MIT Press, Cambridge Mass.

12. Chomsky, N. (2000). New horizons in the study of language and mind. (p.12). Cambridge, UK: Cambridge university press. https://doi.org/10.1017/CBO9780511811937

13. Chomsky, N. (2009). Cartesian Linguistics: A chapter in the history of rationalist thought. (101-110). Third edition. America: Cambridge university press. https://doi.org/10.1017/CBO9780511803116

14. Cook, V. C., \& Newson, M. (2007). Chomsky's universal grammar: An introduction. (pp.9-133). Oxford: Blackwell.

15. Eubark, L. (1996). Negation in early German- English interlanguge: More valueless features in the L2 initial state. Second language research, 12, 73-106. https://doi.org/10.1177/026765839601200104

16. Gedik, M. (2018). The scope of Wh-phrases in Turkish. Available at https://www.researchgate.net/publicatio $\mathrm{n} / 328428833$

17. Goodluck, H. (1991). Language acquisition. A linguistic introduction, Oxford: Blackwell. 
18. Hornby, A. S. (2010). Oxford Advanced Learner's Dictionary. (p.130). New York: Oxford University Press.

19. Jalal, S. (2012). The acquisition of multiple wh-questions by natives and non-natives. The international journal of social sciences and interdisciplinary research, 1(10), 1-3.

20. Johnson, J. S., \& Newport, E. L. (1991). Critical period effects on universal properties of language: The status of subjacency in the acquisition of a second language. Cognition, 39(3), 215-258. https://doi.org/10.1016/00100277(91)90054-8

21. Klein \& G. Martohardjono, (Eds.), the development of second language grammar: a generative approach. (p.289). Amsterdam: John Benjamin.

22. Klein, E. C. (1995). Evidence for a 'wild'L2 grammar: when PPs rear their empty heads. Applied Linguistics, 16(1), 87-117.

23. Michell, R., \& Myles, F. (1998). Second language learning theory. London: Hodder Arnold.

24. Newport, E. (1990). Maturational constraints on language learning. Cognitive science, 14, 11-28. https://doi.or $\mathrm{g} / 10.1207 / \mathrm{s} 15516709 \operatorname{cog} 1401 \_2$

25. Radford, A. (1994). The syntax of questions in child language. Journal of child language, 21, 211-236. ttps://doi.org/10.1017/S0305000900008722

26. Radford, A. (1997). Syntactic theory and the structure of English. (pp. 211-212). Cambridge: Cambridge university press. https://doi.org/10.1017/CB09781139166706

27. Schachter, J. (1989). Testing a proposed universal. In S. Grass \& J. Schachter (Eds.), Linguistic perspectives on second language acquisition. (pp. 73-88). Cambridge: Cambridge university press. https://doi.org/10.1017/C BO9781139524544.007

28. Schachter, J. (1990). On the issue of closeness in second language acquisition. Second language research, 6 , 93-124. https://doi.org/10.1177/026765839000600201

29. Schwartz, B., \& Sprouse, R. (1996). L2 cognitive states and the full transfer/ full access model. Second language research, 12, 40-72. https://doi.org/10.1177/026765839601200103

30. Tatika, K., Fuji, C., Yang, C. Y. B. (2007). WH-questions in Chinese and Japanese I: Anti Crossing and AntiSuperiorty. Nazan Linguistics, 2(1), 99-112

31. Wu, F. (2008). L1 transfer in processing English subjacency sentences from Chinese focused cleft Whs. Proceedings of the $9^{\text {th }}$ generative approaches to second language acquisition conference (GASLA 2007), ed. Roumyana Slabakova et al. (pp. 267-271). Somerville, MA: Cascadilla proceedings project.

32. Yule, G. (2006). The study of language: thoroughly revised and updated.

33. Yusa, N. (1999). Multiple specifiers and wh-islands effects in L2 acquisition: A preliminary study. In E.C. Klei, and G. Martohardjono, (Eds.), the development of second language grammar: a generative approach. Amsterdam: John Benjamins, pp. 289-315. https://doi.org/10.1075/lald.18.15yus 